\title{
BOMBA DE CALOR COM SISTEMA AUTOMÁTICO PARA CONTROLE DO AR DE SECAGEM
}

\author{
J. V. NICACIO${ }^{1}$, E. C. MELO ${ }^{2}$, A. F. de LACERDA FILHO ${ }^{2}$, J. H. MARTINS ${ }^{2}$ e T. A. \\ PIZZIOLO ${ }^{3}$
}

${ }^{1}$ Departamento de Química - Universidade Federal de Viçosa

${ }^{2}$ Departamento de Engenharia Agrícola - Universidade Federal de Viçosa

${ }^{3}$ Departamento de Engenharia Elétrica - Universidade Federal de Viçosa E-mail para contato: jose.nicacio@ufv.br

\begin{abstract}
RESUMO - A secagem é uma das operações unitárias mais usuais na indústria e a que mais consome energia durante o processamento de diversos produtos. Como a energia é um produto caro e escasso faz-se necessário que seja utilizada de forma mais eficiente possível. Além desta preocupação, é necessário ater-se à qualidade final do produto submetido ao processo, visto que a maioria é sensível à ação do calor e da temperatura, que podem, quando excessivos, causar danos nas características que definem a sua qualidade. Neste trabalho foi desenvolvido um sistema automático para o controle do ciclo de funcionamento de uma bomba de calor de forma a permitir que a mesma fosse utilizada como condicionadora de ar para a operação de secagem. O sistema de controle desenvolvido foi capaz de manter o ar de secagem com temperatura constante e umidade relativa dentro da faixa definida pelo usuário. Em todos os testes de secagem realizados para a validação do sistema de controle o mesmo foi capaz de manter os valores de temperatura e umidade relativa do ar de acordo com os valores escolhidos, dentro da faixa de operação da bomba de calor utilizada, respondendo de forma satisfatória às variações ocorridas nas características psicrométricas do ar ambiente.
\end{abstract}

\section{INTRODUÇÃO}

A secagem é uma das operações unitárias mais usuais na indústria e a que mais consome energia durante o processamento de diversos produtos. No processo industrial de fabricação de papel esta operação é a principal consumidora de energia de toda a planta, sendo responsável por aproximadamente $1 / 3$ (um terço) do consumo total e segundo Brooker et al. (1992) esta é responsável por cerca de $60 \%$ da energia consumida no processo produtivo básico de grãos.

Em alguns casos a secagem é uma operação realizada antes do processamento do produto, como no caso da remoção da água da alumina hidratada $\left(\mathrm{Al}_{2} \mathrm{O}_{3} .3 \mathrm{H}_{2} \mathrm{O}\right)$ utilizada no processo de obtenção do alumínio e na secagem de grânulos de resina de poli(tereftalato de etileno), mais conhecido como PET. Todavia, em boa parte das situações a secagem é o último processamento do produto antes de sua classificação e embalagem como é o caso de produtos agrícolas, açúcar, adubos, gel de sílica, couro curtido a crômio, lã fiada, alumina 
ativada, viscose, tecido de algodão, polpa de sulfito, seda de acetato de celulose e papel.

Existem diversas técnicas de secagem que podem ser aplicadas para secar diferentes produtos. As de aplicação prática sempre utilizam o ar como meio secante, ainda que existam outras formas de realizar a secagem. O ar é usado, na maior parte dos sistemas de secagem, como elemento que entrega calor aos produtos ao mesmo tempo em que extrai a umidade. Assim sendo, as diferentes estratégias diferem apenas na forma como o ar e a energia transitam pelo sistema de secagem (Groff, 2002).

O processo de secagem é teoricamente um processo inerentemente autorregulado, o que significa que se o secador não for submetido a mudanças do ambiente (distúrbios), então o processo irá permanecer em estado permanente. Isto mostra que, aparentemente, um sistema automático de controle pode não ser necessário, mas, conforme observado por Monte (2008), distúrbios ocorrem no processo real de secagem, o que faz com que seja necessário um sistema automático de controle.

Avanços recentes e aplicações em controle de qualidade estatístico têm enfatizado a importância do controle de processo para a manutenção da qualidade do produto submetido ao processo de secagem (Mujumdar e Chen, 2008).

Diante deste cenário, onde se busca um processo de secagem com alta eficiência energética e que possa ser facilmente controlado, tecnologias de secadores que utilizam bomba de calor têm emergido como uma opção atrativa e viável.

Os secadores com bomba de calor extraem o calor latente de vaporização do ar ambiente através da condensação do vapor, quando o ar é forçado a passar pelo evaporador e devolvem a energia retirada neste processo como calor sensível ao ar de secagem, quando este é forçado a passar através do condensador (Mujumdar e Chen, 2008).

Strommen et al. (2002) constataram que secadores com bomba de calor consomem entre 60 a $80 \%$ menos energia do que os secadores convencionais quando operam à mesma temperatura. Isto faz desdes secadores uma opção viável para os usuários que não estão satisfeitos com o elevado consumo de energia dos secadores convencionais (Schmidt et al., 1998).

Secadores com bomba de calor tem sido tema de pesquisa e desenvolvimento para diferentes aplicações, principalmente na área de aquecimento, arrefecimento e secagem. Para melhorar o desempenho do secador com bomba de calor, pesquisas sobre a modificação do sistema e da combinação com outros mecanismos auxiliares tem ganhado destaque.

Secadores com bomba de calor são comprovadamente sistemas de secagem que garantem a qualidade do produto, especialmente alimentos e produtos agrícolas. Nestes secadores é possível controlar a temperatura de secagem, umidade relativa, teor de água do produto, velocidade do ar de secagem e tempo de secagem. Os fatores a serem considerados na melhoria de um secador com bomba de calor são o custo de instalação, o desempenho da secagem, tais como a velocidade do ar, a temperatura de secagem e de umidade relativa, o desempenho do componente híbrido de aquecimento (quando presente), potência necessária para operar o sistema e também período de retorno. Ao melhorar o desempenho do secador com bomba de calor garante-se o aumento da qualidade do produto e a redução do custo de operação da indústria de secagem. (Goh et al., 2011). 


\section{METODOLOGIA}

Este trabalho foi desenvolvido no Laboratório de Processamento Pós Colheita do Departamento de Engenharia Agrícola da Universidade Federal de Viçosa.

Para a realização deste experimento foi utilizada a bomba de calor experimental descrita e utilizada por Monte (2008). A Figura 1 ilustra o diagrama do equipamento.

A trajetória do ar e as modificações a que este é submetido ao percorrer o circuito completo da bomba de calor são ilustrados na Figura 2.
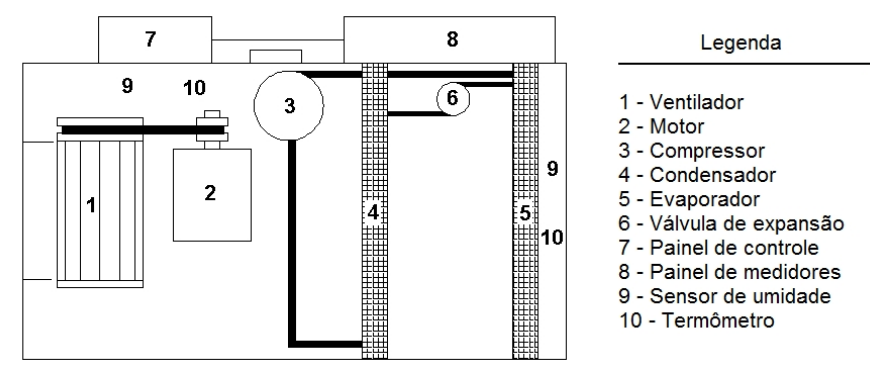

Figura 1 - Diagrama da bomba de calor experimental

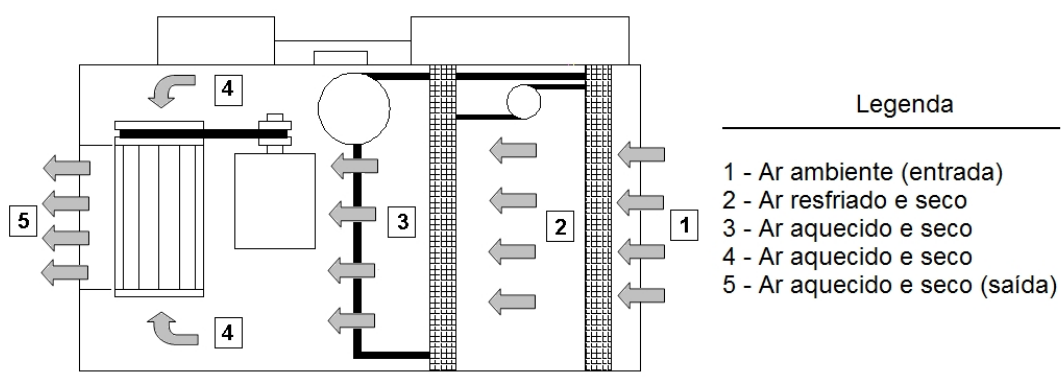

Figura 2 - Trajetória do ar e suas modificações ao passar pela bomba de calor.

Tanto o ventilador quanto o compressor da bomba de calor eram acionados através de inversores de frequência, fato que permitiu que se atuasse na velocidade do ventilador e no ciclo de funcionamento do compressor.

No sistema de secagem com bomba de calor têm-se duas variáveis controladas de interesse que são: a temperatura e a umidade relativa do ar de secagem. Estas variáveis controladas podem ter seus valores modificados através da atuação em duas variáveis manipuladas que são: a velocidade do ventilador e a velocidade do motor do compressor.

Para se verificar a relação entre as variáveis manipuladas e as variáveis controladas foram realizados testes de entrada em degrau no sistema com malha aberta, sendo que em um dos teste o degrau foi aplicado ao motor do ventilador e em outro teste ao compressor.

Para o controle automático da temperatura e da umidade relativa do ar de secagem foi desenvolvido um sistema eletrônico baseado no microcontrolador PIC $18 \mathrm{~F} 4550$ da Microchip. Neste sistema era permitido ao usuário, além de escolher entre os processos de aeração e 
secagem, definir os valores de temperatura e umidade relativa do ar de secagem e o teor de água final do produto submetido ao processo. De posse dos valores de referência fornecidos pelo usuário e dos valores de temperatura e umidade relativa do ar na saída da bomba de calor e do ar de exaustão o sistema atuava no ciclo de funcionamento da bomba de calor através de ação de controle PID discreta conforme ilustrado na Figura 3.

A sintonia do controle PID foi feito com base na resposta ao degrau aplicado no ventilador e na reposta ao degrau aplicado no compressor. Utilizou-se o Método de Resposta ao Degrau de Ziegler e Nichols (Ogata, 1997) para se obter uma estimativa dos valores das constantes do controlador PID e a sintonia fina foi feita por meio do método de tentativa e erro.

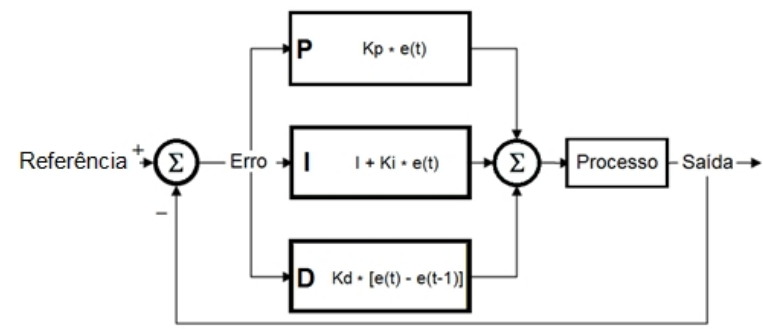

Figura 3 - Representação da ação de controle PID discreta

\section{RESULTADOS E DISCUSSÃO} acoplado.

A figura 4 ilustra o protótipo da bomba de calor utilizada com o sistema de controle

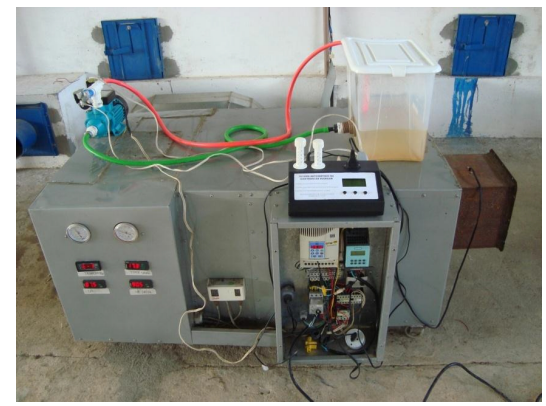

Figura 4 - Protótipo da bomba de calor com o sistema de controle acoplado

\subsection{Ensaios preliminares}

Para verificar a relação entre as variáveis manipuladas e as variáveis controladas, foram realizados dois testes de entrada em degrau no sistema com malha aberta.

No primeiro teste o motor do ventilador foi acionado com o inversor de frequência em $30 \mathrm{~Hz}$ e o compressor foi acionado com o inversor em $60 \mathrm{~Hz}$. Após o sistema entrar em regime permanente de operação aplicou-se uma entrada em degrau no valor de $30 \mathrm{~Hz}$ no inversor do ventilador. As variações de temperatura e umidade relativa do ar na saída da bomba de calor causadas pela aplicação da entrada em degrau no inversor de acionamento do ventilador são ilustradas nas Figuras $5 \mathrm{a}$ e $5 \mathrm{~b}$ respectivamente. 


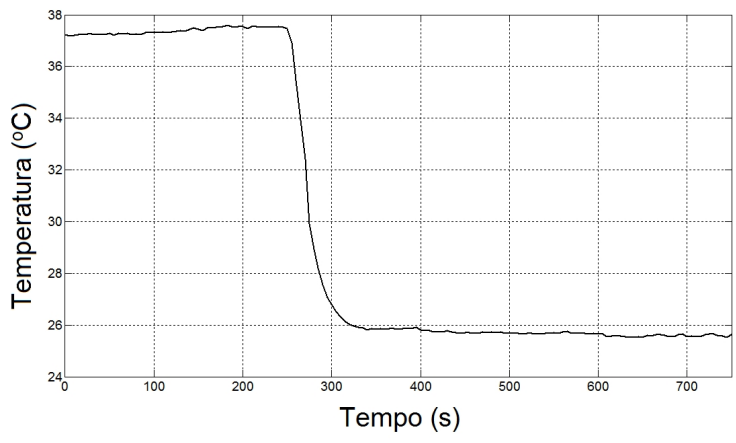

(a)

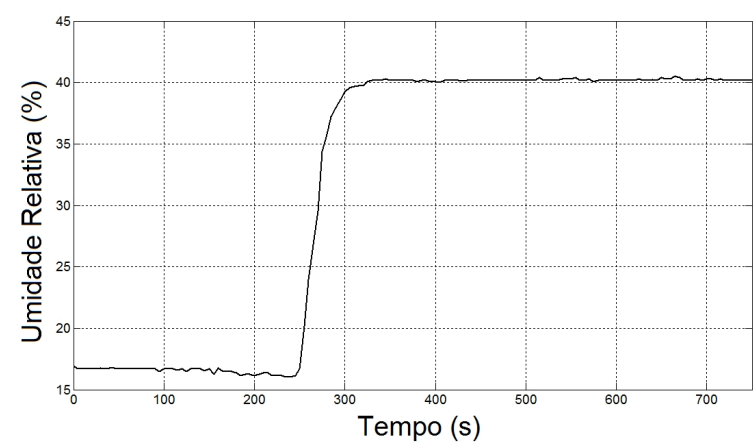

(b)

Figura 5 - (a) Variação da temperatura e (b) variação da umidade relativa

No segundo teste de entrada em degrau o motor do compressor foi acionado com o inversor de frequência em $20 \mathrm{~Hz}$ e o ventilador foi acionado com o inversor em $60 \mathrm{~Hz}$. Após o sistema entrar em regime permanente de operação aplicou-se uma entrada em degrau no valor de $40 \mathrm{~Hz}$ no inversor do compressor. As variações de temperatura e umidade relativa do ar na saída da bomba de calor causadas pela aplicação da entrada em degrau no inversor de acionamento do compressor são ilustradas nas Figuras $6 \mathrm{a}$ e $6 \mathrm{~b}$ respectivamente.

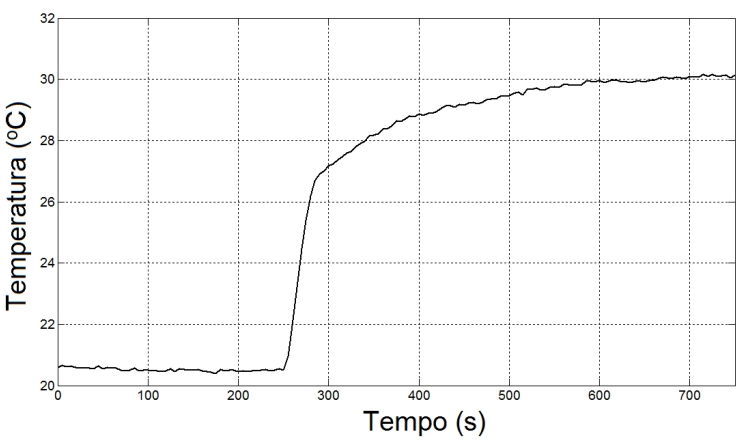

(a)

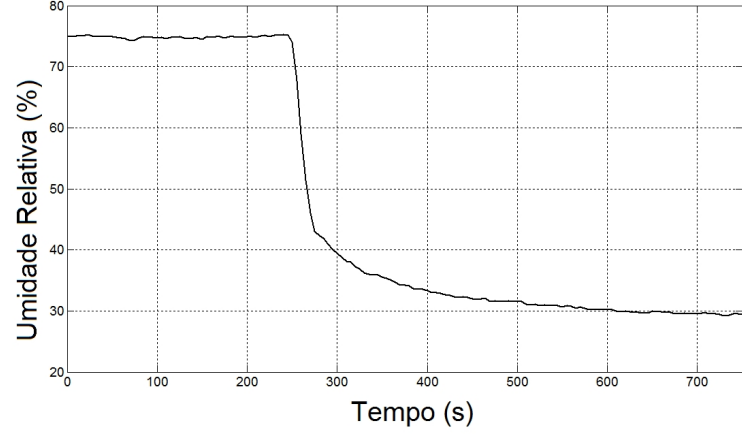

(b)

Figura 6 - (a) Variação da temperatura e (b) variação da umidade relativa

A sintonia do controle PID foi feita com base na resposta ao degrau no ventilador ilustrada na Figura 5 e na resposta ao degrau no ventilador ilustrada na Figura 6. As constantes para os controladores do ventilador e do compressor estão listados na tabela 1 .

Tabela 1 - Constantes dos controladores PID

\begin{tabular}{|c|c|c|c|}
\hline Controlador & kp & ki & kd \\
\hline Ventilador & 0,15 & 0,25 & 0,01 \\
\hline Compressor & 0,45 & 0,75 & 0,05 \\
\hline
\end{tabular}

\subsection{Análise da Resposta Transitória}

Um dos testes realizados teve como objetivo analisar a resposta do sistema a um degrau positivo no valor de referência de temperatura durante o processo de secagem. Neste teste a bomba de calor foi acionada com apenas o ventilador ligado e aguardou-se o tempo necessário para o sistema alcançar o regime permanente de operação. A referência de temperatura foi definida em $30{ }^{\circ} \mathrm{C}$ e a de umidade relativa em $30 \%$. As Figuras $7 \mathrm{a}$ e $7 \mathrm{~b}$ 
ilustram as respostas de temperatura e umidade relativa na saída da bomba de calor, respectivamente.

De acordo com Ogata (1997) um sistema de controle PID bem sintonizado não deve apresentar sobressinal superior a $25 \%$ do valor do degrau aplicado, assim como não deve apresentar mais que quatro períodos de oscilação (Mujumdar e Chen, 2008).

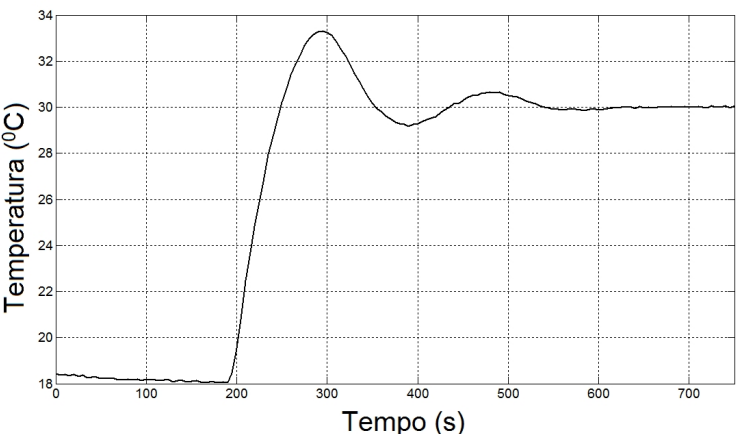

(a)

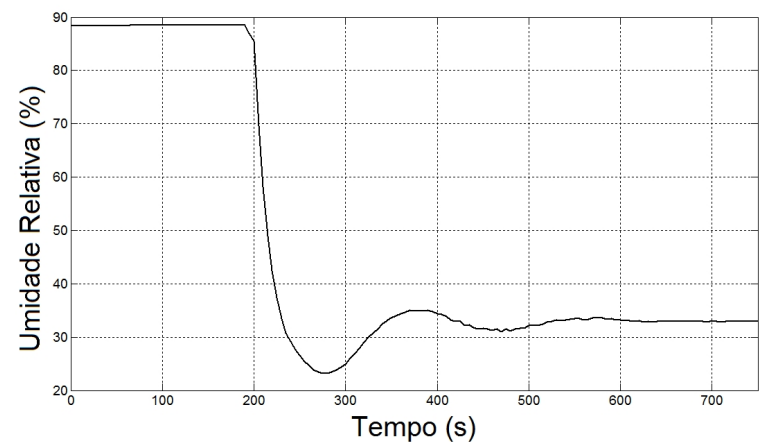

(b)

Figura 7 - (a) Resposta transitória da temperatura e (b) da umidade do ar na saída da bomba de calor devida à aplicação do degrau positivo

De acordo com a Figura 7a, antes de se aplicar o degrau no valor de referência de temperatura, a temperatura do ar na saída do secador estava próxima a $18{ }^{\circ} \mathrm{C}$. Logo, como o valor de referência foi ajustado em $30^{\circ} \mathrm{C}$, temos que o degrau aplicado foi de $12^{\circ} \mathrm{C}$. Observase pela figura $7 \mathrm{a}$ que o valor máximo de temperatura atingido foi de aproximadamente $33{ }^{\circ} \mathrm{C}$, o que dá um sobre sinal de $3{ }^{\circ} \mathrm{C}$, que corresponde a exatamente $25 \%$ do valor do degrau aplicado. Observa-se também a presença de apenas dois períodos de oscilação.

Analisando o gráfico da Figura $7 \mathrm{~b}$ verifica-se que antes de se acionar o sistema de controle a umidade relativa do ar estava com valores próximos a $88 \%$. Como a referência de umidade relativa foi de $30 \%$, foi aplicado um degrau de $58 \%$. Observa-se pela Figura $7 \mathrm{~b}$ que o valor mínimo de umidade relativa atingido durante o transitório foi em torno de $24 \%$, o que dá um sobressinal de $6 \%$ de umidade relativa e equivale a $10,3 \%$ do valor do degrau aplicado. Neste caso também se observa que não há presença de mais de quatro períodos de oscilação. Observa-se também que embora o valor de referência tenha sido de $30 \%$ de umidade relativa, devido ao sistema ter sido programado para priorizar a manutenção da temperatura constante, a melhor aproximação que se conseguiu foi $33 \%$ de umidade relativa.

\subsection{Análise da operação em regime permanente}

Após diversos testes e análise do comportamento transitório do sistema automático de controle para condicionamento de ar de secagem utilizando bomba de calor, foram realizados testes para análise do regime permanente de operação do sistema. Do ponto de vista prático, a capacidade do sistema em manter as variáveis controladas de acordo com os valores de referência durante o regime permanente de operação é de suma importância, já que, diferentemente do regime transitório onde as oscilações não duram tempo suficiente para causar qualquer alteração nas características dos produtos, oscilações de grande duração podem ocasionar secagem excessiva ou umedecimento dos mesmos. Também devido a curta duração do regime transitório, este não está sujeito a fortes distúrbios referentes a variações 
nas condições ambientais, fato este que afeta fortemente o sistema operando em regime permanente e põe a prova sua capacidade de resposta a tais distúrbios.

O seguinte teste realizado teve como objetivo analisar a capacidade do sistema de manter a temperatura e umidade relativa do ar de saída de acordo com o valor de referência durante um longo período de tempo. Assim como no primeiro teste realizado para análise do regime transitório, o sistema foi ajustado para manter a temperatura em $30{ }^{\circ} \mathrm{C}$ e $30 \%$ de umidade relativa. Nos testes de operação em regime permanente, além de se tomar os dados referentes às características psicrométricas do ar na saída da bomba de calor, tomou-se também os dados referentes ao ar ambiente, de forma a se verificar as variações ocorridas no decorrer do teste e a resposta do sistema a estes distúrbios. Os dados foram coletados no período de $07 \mathrm{~h} 50 \mathrm{~min}$ às $18 \mathrm{~h} 20 \mathrm{~min}$. A Figuras $8 \mathrm{a}$ e $8 \mathrm{~b}$ ilustram a temperatura e a umidade relativa do ar de secagem na saída da bomba de calor e a variação das mesmas no ambiente.

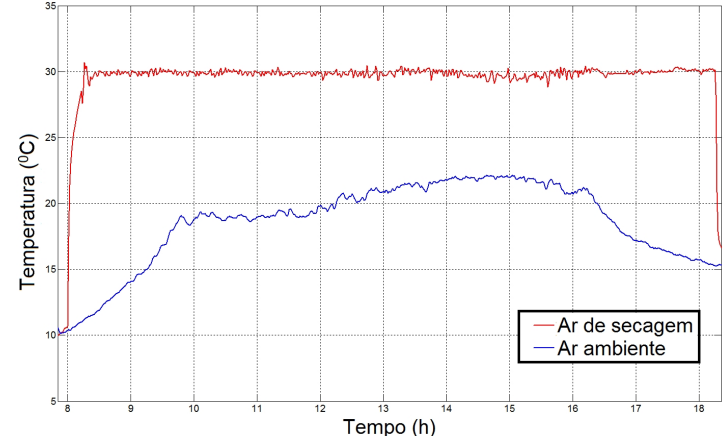

(a)

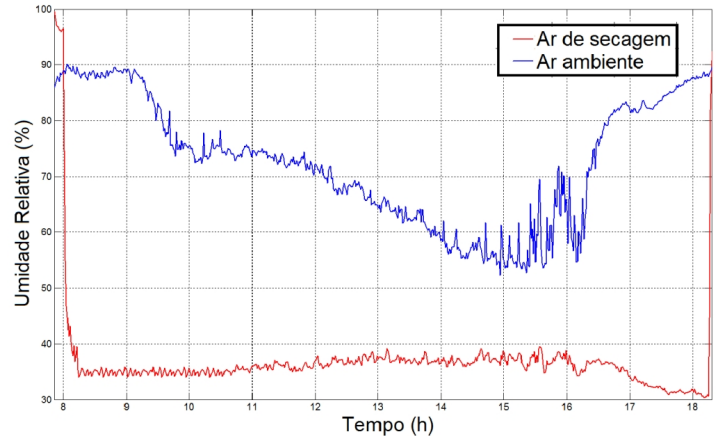

(b)

Figura 8 - (a) Resposta permanente da temperatura e (b) da umidade relativa do ar

\section{CONCLUSÕES}

Com base nos resultados obtidos nos diversos testes realizados pode-se concluir que o sistema de controle projetado se mostrou eficiente para controlar adequadamente as características psicrométricas do ar de secagem, tornando-se desta forma uma poderosa ferramente para ser utilizado em processos onde se buscam alta eficiência e preservação das principais características do produto submetido à secagem.

\section{AGRADECIMENTOS}

Os autores agradecem ao CNPq, à Capes e à Fapemig pelo suporte financeiro.

\section{REFERÊNCIAS}

BROOKER, D. B.; BAKKER-ARKEMA, F. W.; HALL, C. W. Drying and Storage of Grains and Oilseeds. $1^{\mathrm{a}}$ Edição. New York: AVI Book, 1992. 450p.

GOH, L. J.; OTHMAN, M. Y.; MAT, S.; RUSLAN, H.; SOPIAN, K. Review of heat pump systems for drying application. Renewable and Sustainable Energy Reviews. v. 15, p. 47884796. 2011. 
GROFF, R. Secagem de grãos. SEED News. v. 6, n. 2, p. 1-6. Pelotas, 2002.

MONTE, J. E. C. Desenvolvimento e análise de um sistema de controle para bomba de calor utilizada em processos agrícolas. Viçosa, MG. Tese (Doutorado em Engenharia Agrícola) Universidade Federal de Viçosa, 2008.

MUJUMDAR, A. S.; CHEN, X. D. Drying Technologies in Food Processing. $1^{\text {a }}$ Edição. Singapura: Blackwell Publishing Ltd., 2008. 326p.

OGATA, K. Engenharia de controle moderno. $3^{\text {a }}$ Edição. São Paulo: Prentice Hall, 1997. $677 \mathrm{p}$.

SCHMIDT, E. L.; KLOCKER K.; FLACKE N.; STEIMLE F. Applying the transcritical $\mathrm{CO}_{2}$ process to a drying heat pump. Int J Refrig. v. 21, n. 3, p. 202-211. Grã-Bretanha, 1998.

STROMMEN, I.; EIKEVIK, T. M.; ALVES-FILHO, O.; SYVERUD, K.; JONASSEN, O. Low temperature drying with heat pumps new generations of high quality dried products. 13th International drying symposium; 2002. 